\title{
System Mass Variation and Entropy Generation in 100-kWe Closed-Brayton-Cycle Space Power Systems
}

\author{
Michael J. Barrett ${ }^{1}$ and Bryan M. Reid ${ }^{1,2}$ \\ ${ }^{I}$ Power and On-Board Propulsion Technology Division, NASA Glenn Research Center, Cleveland, OH 44135 \\ ${ }^{2}$ Department of Aerospace Engineering, University of Michigan, Ann Arbor, MI 48109 \\ (216) 433-5424, Michael.J.Barrett@nasa.gov
}

\begin{abstract}
State-of-the-art closed-Brayton-cycle (CBC) space power systems were modeled to study performance trends in a trade space characteristic of interplanetary orbiters. For working-fluid molar masses of 48.6, 39.9 and 11.9 $\mathrm{kg} / \mathrm{kmol}$, peak system pressures of 1.38 and $3.0 \mathrm{MPa}$ and compressor pressure ratios ranging from 1.6 to 2.4 , total system masses were estimated. System mass increased as peak operating pressure increased for all compressor pressure ratios and molar mass values examined. Minimum mass point comparison between $72 \% \mathrm{He}$ at $1.38 \mathrm{MPa}$ peak and $94 \% \mathrm{He}$ at 3.0 MPa peak showed an increase in system mass of 14\%. Converter flow loop entropy generation rates were calculated for 1.38 and $3.0 \mathrm{MPa}$ peak pressure cases. Physical system behavior was approximated using a pedigreed NASA-Glenn modeling code, Closed Cycle Engine Program (CCEP), which included realistic performance prediction for heat exchangers, radiators and turbomachinery.
\end{abstract}

\section{INTRODUCTION}

Fission-based space nuclear power systems can be subdivided into four primary subsystems: reactor, power conversion, heat rejection, and power management and distribution (PMAD). The conceptual design of a space nuclear power system involves a highly complicated, system-wide optimization of mass, volume, and energy transport that must also address a host of life-cycle issues ranging from launch-processing to system deactivation and decommissioning. To be useful, subsystem designs must be evaluated in the context of integrated system performance. For example, conditions that characterize maximum subsystem efficiency do not always yield the lowest overall system mass. In fact, if imposed on the overall system, an independently derived minimum mass operating condition for a single subsystem can easily result in increased total mass.

Closed-Brayton-cycle (CBC) power conversion is one method that can be used in space power systems. Brayton system conceptual designs for milliwatt to megawatt power converters have been developed (Baggenstoss and Ashe, 1992; Harty, et al., 1993; Shaltens and Mason, 1996; Hyder et al., 2000; Mason, 2003). When optimizing a CBCbased power conversion system (PCS), numerous features affect overall system performance; a partial list of influential factors includes turbomachinery efficiency, heat exchanger effectiveness, working-fluid composition and cycle temperatures and pressures. The literature holds over 250 works on Brayton-related space power system topics presented in the past 30 years. A few studies address the adaptability of Brayton systems to different heat sources; principal heat-source differences include thermal power output level and cooling configuration (for example, liquid pumped loop, heat pipe, or direct gas). Three works that serve as representative examples are Tilliette (1988), Owen (1989) and Baggenstoss and Ashe (1992).

Tilliette (1988) examined 10 different 25-kWe-class CBC PCS configurations - five with NaK-cooled reactors and five with direct-gas cooling. Recuperated and non-recuperated systems were evaluated; fast and thermal reactor spectrums were included. For all 10 cases in Tilliette's work, a He-Xe mixture with molar mass of 40 was used as the working fluid. Tilliette demonstrated that a $\mathrm{CBC}$ was adaptable for all of the configurations examined. Owen (1989) presented 10-kWe- to $100-\mathrm{kWe}$-class CBC PCS conceptual designs using SP-100 technology. Reactor cooling schemes noted include pumped loop, heat pipe and direct gas. Owen summarized advantages of the CBC system over a 100-kWe thermoelectric converter system. Molar mass of the $\mathrm{CBC} \mathrm{He}-\mathrm{Xe}$ mixture was not reported. Baggenstoss and Ashe (1992) gave an extensive study of mission design drivers in CBC PCS configurations. They

CP699, Space Technology and Applications International Forum-STAIF 2004, edited by M.S. El-Genk

(C) 2004 American Institute of Physics 0-7354-0171-3/04/\$22.00 
examined five cases with power outputs ranging from 0.5 to $3,300 \mathrm{kWe}$. Heat sources in their study included isotope, solar and reactor. The 100-kWe case used a liquid-metal-cooled reactor based on SP-100 technology; a direct-gas-cooled reactor was examined in the 3,300 kWe case. System mass estimates were given for the five cases assessed. Although working fluid molar mass was identified as an independent variable in the design process, values were not reported.

In the present study of 100-kWe-class CBC space power systems, the objectives are (1) to identify system-level mass trends as peak operating pressure, compressor pressure ratio (CPR) and working fluid composition are varied, and (2) to estimate entropy generation rates in the CBC loop for different operational cases. In a conceptual design, when different reactor cooling schemes are considered (for example, pumped-liquid-cooled versus direct-gas cooled), peak $\mathrm{CBC}$-loop operating pressure and $\mathrm{CBC}$ working fluid molar mass are critical design parameters. Through their influences on fluid properties, these parameters strongly affect heat transfer in the CBC-loop heat exchangers as well as the performance of the turbomachinery. To more easily manage core cooling requirements, designers of direct-gas-cooled reactor subsystems often request CBC working fluid densities and specific heats that are higher than those needed for liquid-metal-cooled reactors. Peak pressure, CPR and fluid composition are some of the key independent design parameters that are used to manipulate the fluid properties. The first objective captures the desire to better understand system-level changes due to variation of these parameters; the second objective allows the evaluation of component-level irreversibilities as the parameters are changed.

In the study that follows, first, the power system model used in the analysis is described and case definitions are given. Model-based conceptual design results for the various cases are then presented; estimated system masses are highlighted. Component- and subsystem-level entropy generation rates are also predicted for the CBC fluid loop. Finally, conclusions are drawn from the quantitative modeling results.

\section{METHOD}

An integrated CBC PCS modeling code developed at the NASA Glenn Research Center (Klann, 1991) was used to evaluate system performance and architecture. The Closed Cycle Engine Program (CCEP) is a pedigreed FORTRAN code that has been refined during years of use in modeling solar-dynamic and nuclear-based CBC space systems. The code was originally developed as a major revision to the Navy/NASA Engine Program (NNEP) - an aircraft gas-turbine design and performance computer program (Fishbach and Caddy, 1975). Although closedsystem modifications were made and component-level submodels were updated, the calculation methods of NNEP were maintained. For additional details about the computational tool, the reader is referred to Fishbach and Caddy (1975), Klann and Staiger (1985), Klann (1991), and Hanlon (1992).

The CCEP code integrates subsystem models for all four elements in the power system. Detailed control of each subsystem configuration is permitted. For example, distributed coolant tube diameter, wall thickness, length and spacing are four of the 35 controllable inputs in the radiator model; heat transfer fin material, length, and pitch are among the 36 input controls in the CBC recuperator component-level model. Many input controls allow a range of permissible values to be specified so the code optimization scheme can automatically manipulate the parameter as needed.

At the present time, the lowest fidelity element in the model is the reactor subsystem. Reactor inputs include heat loss fraction, reactor-to-payload distance, lifetime required and shield half angle. Desired outlet total temperature and relative pressure loss $(\Delta P / P)$ are added inputs when modeling gas-cooled reactors. The heat exchanger at the reactor-converter interface is modeled as part of the reactor subsystem; heat transfer fluid and heat source heat exchanger (HSHX) geometry are not specified inputs.

Using CCEP, a "conventional-technology" CBC PCS (configuration and assumptions described hereafter) was modeled and a number of cases were evaluated by varying peak system pressure, compressor pressure ratio (CPR), and working fluid composition. Electrical power output, radiator sink temperature and turbine inlet temperature were held constant for all cases. The results for each case were compared to a baseline reference to facilitate parametric illustration of relative trends. 


\section{CBC PCS Physical Model Description}

Present CBC PCS model parameters are intentionally chosen to represent existing "state-of-the-art" technology. Although advanced materials and technology may be needed to support future missions (Pietsch and Brandes, 1989; Barrett, 2003), general system trends uncovered using a conventional-technology model still yield meaningful implications for advanced-technology systems. In fact, trends can also suggest critical technology-development focus areas.

In the state-of-the-art system, turbine inlet temperature is held at $1150 \mathrm{~K}$ to permit the use of nickel-based superalloys as converter hot-section materials. Refractory metal alloys are needed only in the reactor subsystem; a liquid-metal-cooled reactor is used. (The use of a liquid-metal reactor model is addressed further in the section titled "Case Definition.") The converter turbomachinery consists of a single-stage centrifugal compressor and a singlestage radial turbine; turbomachinery maps are used to determine component performance. The turbine-alternatorcompressor (TAC) is integrated on a single rotating shaft supported by gas-foil thrust and journal bearings. Constant electrical load is maintained using control electronics and a parasitic load radiator. The converter working fluid is a He-Xe mixture; composition varies with the specified molar mass, $\mathcal{M}$. Ducts are sized based on allowable system pressure-drops; wall thicknesses are determined using maximum allowable hoop stresses with a safety factor of 2.0. Heat exchangers in the converter subsystem are counterflow type and of conventional metallic construction. An aluminum-face-sheet radiator using aluminum honeycomb construction with panel geometry similar to the photovoltaic radiator on the International Space Station (NASA Lewis Research Center, 1993) is employed in the heat rejection subsystem (HRS). The HRS fluid loop contains n-heptane coolant. Far-field ("sink") temperature for the HRS is $200 \mathrm{~K}$.

The present PCS model represents a single-string CBC converter with a single pumped loop in the HRS. The zeroredundancy system is chosen to evaluate fundamental mass trends in the most basic system (often used in sizing exercises); an actual flight system would need to meet redundancy requirements specified by the flight project. In all cases examined, steady state power output delivered from the PMAD subsystem to the load is $100 \mathrm{kWe}$.

\section{Case Definition}

For reference purposes, a baseline configuration is presented first. System mass variations and other analysis results are then compared with the baseline configuration. A liquid-metal reactor is used in all cases examined. Because of the thermal power ranges involved, the maximum estimated mass variation of the reactor subsystem is only $0.07 \%$ of the baseline total system mass. (Reactor mass is effectively the same in all cases examined.) This allows us to attribute the resulting total system mass variations to changes in only the power conversion, heat rejection, and PMAD subsystems. Therefore, when evaluating the results in the context of considering liquid-metal-cooled versus direct-gas-cooled reactors, the mass increases shown are still relevant if the system operating conditions (as identified in the figures) are representative of those needed for the different cooling schemes.

\section{Baseline}

The baseline reference case is defined by the annotated system schematic shown in Fig. 1. The CBC PCS state points shown were derived from a planetary science mission study recently conducted at NASA (Mason, 2003). The baseline configuration is a system with a peak operating pressure of $1.38 \mathrm{MPa}, \mathrm{CPR}$ equal to 2.0 and working fluid molar mass of $39.9 \mathrm{~kg} / \mathrm{kmol}$.

\section{Variations}

The model was used to evaluate a series of cases encompassing variations in $P_{\text {peak }}$, CPR and $\mathcal{M}$. Peak pressures of 1.38 and $3.0 \mathrm{MPa}$, CPRs ranging from 1.6 to 2.4 , and $\mathcal{M}$ values of 39.9 ( $72 \% \mathrm{He}$ by volume), 48.55 (65\% $\mathrm{He}$ ) and $11.9 \mathrm{~kg} / \mathrm{kmol}(94 \% \mathrm{He})$ were examined. 


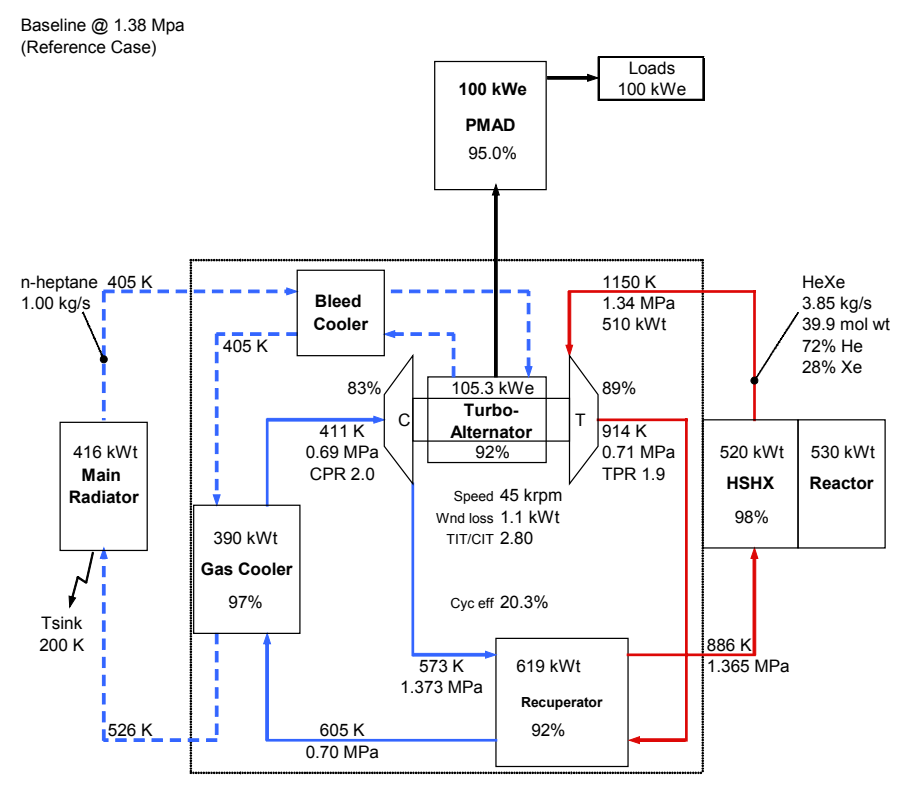

FIGURE 1. CBC PCS Single-String Baseline Reference Case.

\section{RESULTS AND DISCUSSION}

System mass dependence on the identified independent parameters is addressed first. Presentation of componentspecific and combined CBC loop entropy generation rates then follows.

\section{Mass Dependence on Peak Pressure, CPR and Molar Mass}

Figures 2 through 5 show the $P_{\text {peak }}, \mathrm{CPR}$ and $\mathcal{M}$ dependence of system mass relative to the baseline condition. For $\mathcal{M}$ equal to $39.9 \mathrm{~kg} / \mathrm{kmol}$ and $P_{\text {peak }}$ at $1.38 \mathrm{MPa}$, Fig. 2 suggests that a deviation greater than $5 \%$ above or below a CPR of 2.0 leads to observable mass penalties. For the $3.0 \mathrm{MPa} P_{\text {peak }}$ case, the minimum mass point (again near a CPR of 2.0 ) carries a $7.8 \%$ penalty. Error bars representing $15 \%$ of the mass increase percentage are shown on the $1.38 \mathrm{MPa}$ case in Fig. 2 for reference.

If $\mathcal{M}$ is increased to $48.6 \mathrm{~kg} / \mathrm{kmol}$, similar system mass trends result (displayed in Fig. 3). Minimum mass point penalties for $P_{\text {peak }}$ values of 1.38 and $3.0 \mathrm{MPa}$ do not change significantly from the earlier case of $\mathcal{M}=39.9$ $\mathrm{kg} / \mathrm{kmol}$. However, the minimum mass points are located at slightly higher CPR values.

In attempting to estimate system performance for $\mathcal{M}$ of $11.9 \mathrm{~kg} / \mathrm{kmol}(94 \% \mathrm{He})$ and $P_{\text {peak }}$ at $1.38 \mathrm{MPa}$, the requisite turbomachinery dimensionless characteristics were outside the realm of convergence for the code's current turbomachinery performance maps. At $3.0 \mathrm{MPa}$, however, the performance maps were adequate to yield the converged results illustrated by the upper curve in Fig. 4. (The $1.38 \mathrm{MPa}, 39.9 \mathrm{~kg} / \mathrm{kmol}$ results from Fig. 2 are repeated as the lower curve in Fig. 4 for reference.) For the $94 \%$-He composition, the minimum mass penalty is approximately $14 \%$; the minimum mass point occurs slightly below a CPR of 1.6 .

Figure 5 summarizes the minimum mass point results for two peak pressures and varying fluid composition; the CPR values vary for the locus of points comprising each curve. In Fig. 5 and in all other cases showing mass increases over the baseline, the increases result primarily from the interrelationship between turbomachinery efficiencies, recuperator effectiveness and the required heat rejection area. 


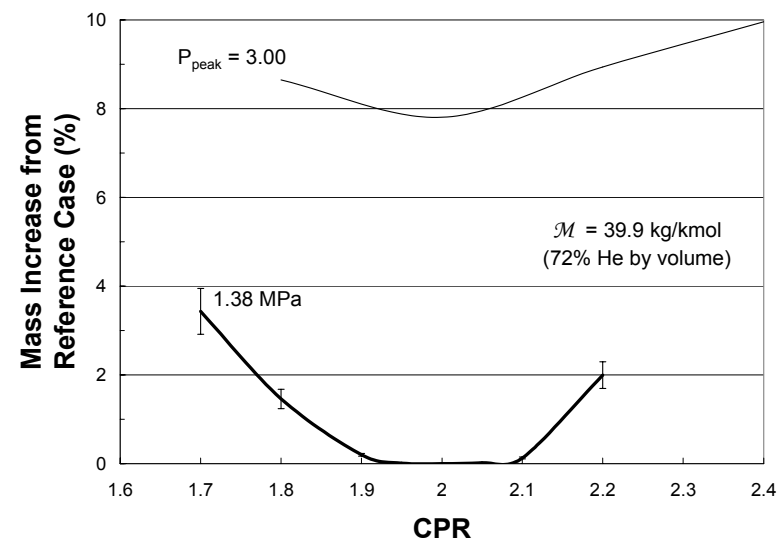

FIGURE 2. Mass Dependence on $\mathrm{CPR}$ and $\mathrm{P}_{\text {peak }}$ for $\mathcal{M}=39.9 \mathrm{~kg} / \mathrm{kmol}(72 \% \mathrm{He}$ vol.).

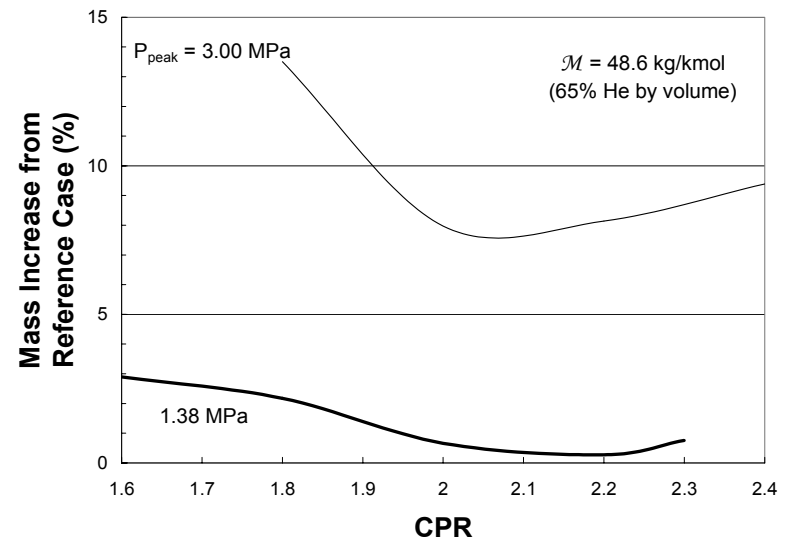

FIGURE 3. Mass Dependence on CPR and $\mathrm{P}_{\text {peak }}$ for $\mathcal{M}=48.6 \mathrm{~kg} / \mathrm{kmol}(65 \% \mathrm{He}$ vol.).

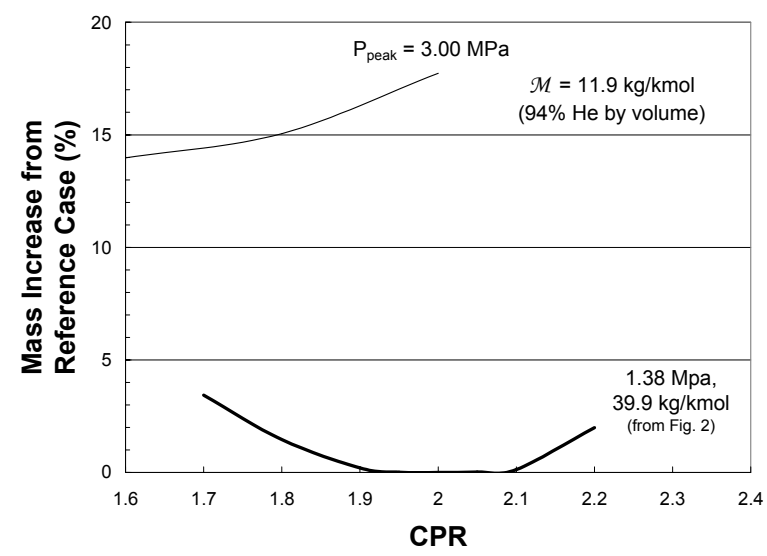

FIGURE 4. Mass Dependence on CPR for $P_{\text {peak }}=3.0 \mathrm{MPa}$ and $\mathcal{M}=11.9 \mathrm{~kg} / \mathrm{kmol}(94 \% \mathrm{He}$ vol.). 


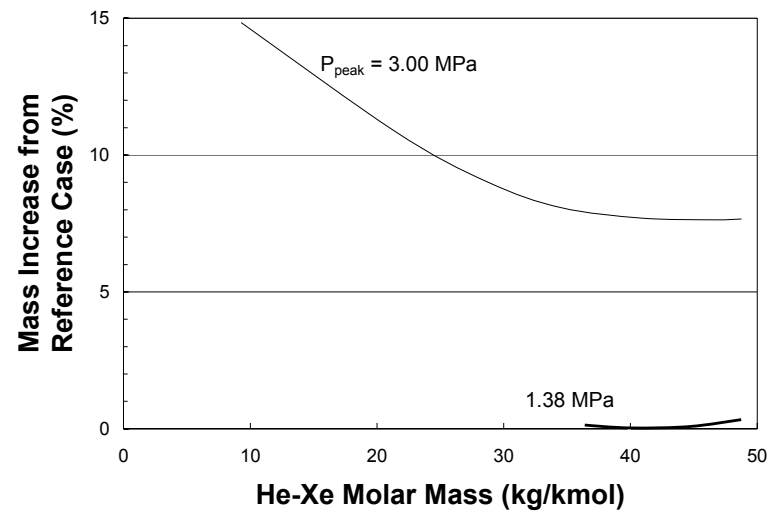

FIGURE 5. Minimum System Mass Dependence on Molar Mass (Various CPR Values).

\section{Entropy Generation in Minimum Mass Cases}

To examine estimated irreversibility contributions from components in the CBC flow loop, entropy generation rates, $\dot{S}_{g e n}$, and entropy generation numbers, $N s$, for the minimum mass cases at peak pressures of $1.38 \mathrm{MPa}$ and $3.0 \mathrm{MPa}$ are presented in Figs. 6 and 7. In the analysis, both the liquid and gas streams of the Gas Cooler were evaluated; however, only the gas stream in the HSHX was assessed. Note that in the lower-pressure case, the compressor is the largest contributor to $\dot{S}_{g e n}$; at $3.0 \mathrm{MPa}$, the recuperator is as large a contributor. This may suggest further recuperator-focused optimization runs over an expanded effectiveness range at the $3.0 \mathrm{MPa}$ condition need to be executed. Likewise, the markedly larger $N s$ for the gas cooler in the lower-pressure case also suggests further study of its operating point is warranted. However, recall that minimizing irreversibilities does not always yield a lower system mass estimate.

The subsystem $\dot{S}_{\text {gen }}$ increases $62 \%$ when moving from $1.38 \mathrm{MPa}$ to $3.0 \mathrm{MPa}$ peak pressure; the increase generally reflects elevated component irreversibilities at the higher $P_{\text {peak }}$. In both $P_{\text {peak }}$ cases, the dimensionless entropy generation numbers, $N s=\dot{S}_{g e n} / \dot{m} c_{p}$, are similar except for the notable recuperator increase and gas cooler decrease in the $3.0 \mathrm{MPa}$ case.

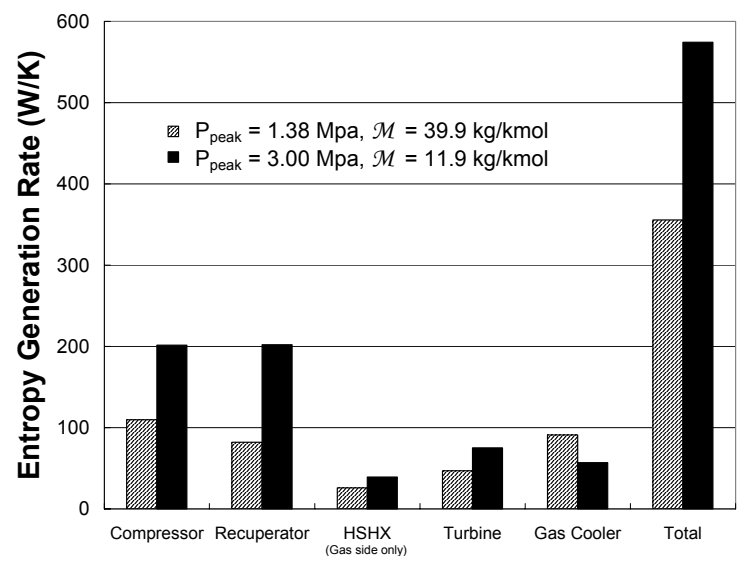

FIGURE 6. Entropy Generation Rate Contributions from CBC Flow Loop Components. 


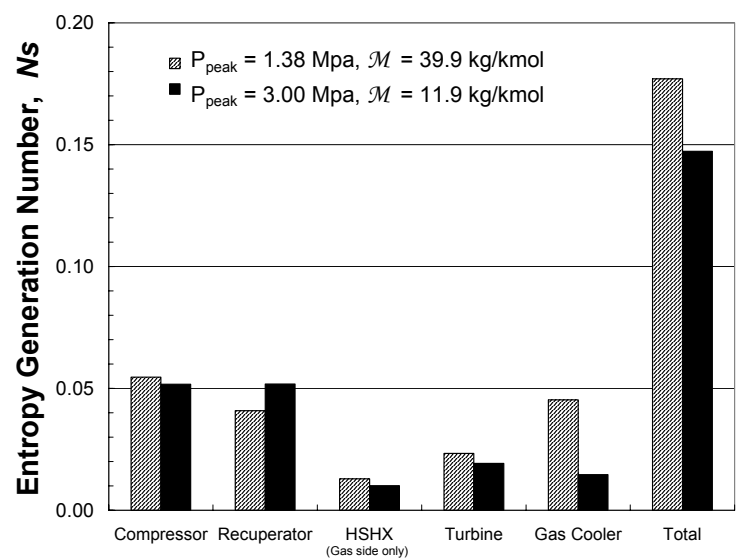

FIGURE 7. Entropy Generation Numbers for CBC Flow Loop Components.

\section{CONCLUSIONS}

System mass increased as peak operating pressure was increased from $1.38 \mathrm{MPa}$ to $3.0 \mathrm{MPa}$ for all compressor pressure ratios and molar mass values examined. In a single-string CBC PCS, minimum mass point comparison between $72 \% \mathrm{He}$ at $1.38 \mathrm{MPa}$ peak and $94 \% \mathrm{He}$ at $3.0 \mathrm{MPa}$ peak showed an increase of $14 \%$.

Over the range of peak pressures and compressor pressure ratios evaluated, system mass generally increased as molar mass decreased. However, at 1.38 MPa peak pressure, negligible mass increase was noted between 48.6 and $39.9 \mathrm{~kg} / \mathrm{kmol}$ operating points. Restrictions in existing turbomachinery maps limited the range of molar masses that could be evaluated at the lower peak operating pressure.

At respective minimum mass points, converter subsystem entropy generation increased when peak pressure increased and molecular weight simultaneously decreased. The converter subsystem entropy generation rate doubled from the $72 \% \mathrm{He}$ at $1.38 \mathrm{MPa}$ peak case to the $94 \% \mathrm{He}$ at $3.0 \mathrm{MPa}$ peak condition; the values were 330 and $680 \mathrm{~W} / \mathrm{K}$, respectively. Except for a rise in the recuperator value for the $3.0 \mathrm{MPa}$ case, dimensionless entropy generation numbers were similar between the two cases.

\section{NOMENCLATURE}

$c_{p}=$ specific heat $[\mathrm{J} /(\mathrm{kg} \mathrm{K})]$

$\mathrm{CPR}=$ compressor pressure ratio

$\dot{m}=$ mass flow rate $(\mathrm{kg} / \mathrm{s})$

$\mathcal{M}=$ molar mass $(\mathrm{kg} / \mathrm{kmol})$

$N s \quad=$ entropy generation number $\left(=\dot{S}_{g e n} / \dot{m} c_{p}\right)$

$P \quad=$ pressure $(\mathrm{MPa})$

$\dot{S}_{\text {gen }}=$ entropy generation rate $(\mathrm{W} / \mathrm{K})$

\section{ACKNOWLEDGMENT}

Project Prometheus, NASA's Nuclear Systems Program, supported the work described within this paper, in whole or part, as part of the program's technology development and evaluation activities. Any opinions expressed are those of the authors and do not necessarily reflect the views of Project Prometheus. 


\section{REFERENCES}

Baggenstoss W.G., and Ashe, T.L., "Mission Design Drivers for Closed Brayton Cycle Space Power Conversion Configuration," ASME Journal of Engineering for Gas Turbines and Power, 721-726 (1992).

Barrett, M.J., "Performance Expectations of Closed-Brayton-Cycle Heat Exchangers in 100-kWe Nuclear Space Power Systems," in proceedings of 1st International Energy Conversion Engineering Conference (IECEC 2003), AIAA Publications, Reston, VA, 2003, Paper \# AIAA-2003-5956.

Fishbach, L.H., and Caddy, M.J., NNEP - The Navy/NASA Engine Program, NASA-TM X-71857, NASA Lewis Research Center, Cleveland, Ohio, 1975.

Hanlon, C.H., "Optimization of Closed Brayton Cycles for Space Power Generation," in proceedings of Intersociety Energy Conversion Engineering Conference (IECEC 1992), SAE Publications, Warrendale, PA, 1992, v. 1, pp. 51-55.

Harty, R.B., Otting, W.D., and Kudija, C.T., "Applications of Brayton Cycle Technology to Space Power," in proceedings of Intersociety Energy Conversion Engineering Conference (IECEC 1993), ACS Publications, Washington, DC, 1993, pp. 463-467.

Hyder, A.K., Wiley, R.L., Halpert, G., Flood, D.J., and Sabripour, S., Spacecraft Power Technologies, Imperial College Press, London, 2000, pp. 332-340.

Klann, J.L., and Staiger, P.J., "Design Tradeoffs for a Space Station Solar-Brayton Power System," in proceedings of Intersociety Energy Conversion Engineering Conference (IECEC 1985), SAE Publications, Warrendale, PA, 1985, v. 1, pp. 84-97.

Klann, J.L., Closed Cycle Engine Program Operational Manual, NASA Lewis Research Center, Cleveland, Ohio, 1991.

Mason, L.S., “A Power Conversion Concept for the Jupiter Icy Moons Orbiter," in proceedings of 1st International Energy Conversion Engineering Conference (IECEC 2003), AIAA Publications, Reston, VA, 2003, Paper \# AIAA-2003-6007.

NASA Lewis Research Center, Solar Dynamic Power System Branch, Solar Dynamic Power System for Space Station Freedom, NASA Reference Publication 1310, NASA Lewis Research Center, Cleveland, Ohio, 1993, pp. 124-126.

Owen, D.F., "SP-100/Brayton Power System Concepts," in proceedings of Intersociety Energy Conversion Engineering Conference (IECEC 1989), IEEE Publications, Los Alamitos, CA, 1989, pp. 1257-1262.

Pietsch, A., and Brandes, D.J., "Advanced Solar Brayton Space Power Systems," in proceedings of Intersociety Energy Conversion Engineering Conference (IECEC 1989), IEEE Publications, Los Alamitos, CA, 1989, pp. 911-916.

Shaltens R.K., and Mason, L.S., "Early Results from Solar Dynamic Space Power System Testing," AIAA Journal of Propulsion and Power, 852-858 (1996).

Tilliette, Z.P., "Adaptability of Brayton Cycle Conversion Systems to Fast, Epithermal and Thermal Spectrum Space Nuclear Reactors," in proceedings of Intersociety Energy Conversion Engineering Conference (IECEC 1988), ASME Publications, New York, 1988, pp. 197-202. 